\title{
The Expansion of Telephone and Supply Systems.
}

' $\mathrm{HE}$ problems that arise in connexion with the expansion of telephone systems are in some respects analogous to the corresponding problems in the supply of electric lighting. The Institution of Electrical Engineers therefore arranged on Jan. 10 that papers on each of these subjects should be read at the same meeting so that the solutions adopted by the telephone engineers might be compared with those adopted by the supply engineers. The title given to each paper was "The Anticipation of Demand, and the Economic Selection, Provision, and Lay-out of Plant."

Mr. J. G. Hines discussed the telephone system and Capt. Donaldson the electric power system. The first problem that has to be solved in both systems is the forecasting of the probable number and distribution of subscribers that will exist in a given area at a given time. Once this is settled, the provision of a lay-out which will ensure an efficient service at a minimum cost over this period is a technical problem which should admit of a rigorous mathematical solution.

Secondary problems arise, however. In connexion with telephony there is the 'busy hour,' and in connexion with electric supply there is the "peak load.' In trunk line telephony the difficulty is sometimes met by having a special tariff so as to induce subscribers to communicate at the less busy hours, and occasionally, in electric supply, by means of meters which register more rapidly at stated times. There are many points of dissimilarity between the two problems. When a house has been wired for the electric light, it is most probable that there will be always a user in that house. In the case of telephone supply, especially in private dwellings, a change of occupier usually results in the telephone circuit serving the premises being given up. This involves recovery of the apparatus and the temporary or permanent abandonment of all the internal wiring, which is always provided by the Post Office.

In large cities high-class property is often found next door to poor dwellings. Before the period covered by the Post Office forecast has expired, the smaller properties may be pulled down and replaced by blocks of flats or business premises, each requiring many telephones. It is necessary, therefore, to make detailed inquiries about possible alterations to property. Certain businesses like stockbroking and bookmaking are very fluctuating. When there is a rush of work the number of telephones may be increased five times, and then when the depression comes they are given up.

The data given show why overhead transmission is desired by engineers. A wire made of cadmium copper and weighing $40 \mathrm{lb}$. per mile used overhead has a speech transmission efficiency equal to that of a $200 \mathrm{lb}$. per mile underground cable. Public authorities, however, are increasingly reluctant to give permission to erect poles in public footways. Capt. Donaldson said that the telephone problem is the more difficult, because each consumer must have his own individual pair of wires at least so far as the first telephone exchange.

If the electric lighting stations built twenty-five years ago had been ten times larger, it would have been in the country's interest. The replacement of reciprocating engines by the turbine has made it possible to accommodate considerably larger units of supply in the original engine rooms, but in many cases considerable alterations have had to be made. Capt. Donaldson pointed out the fallacy of always replacing an engine by one of double the size ; it is always necessary to assume that one engine may be out of commission. Hence the maximum reserve of power is obtained when all the engines are of equal size. The general situation is rapidly passing out of the hands of the smaller undertakers. Power engineers by careful study of the yearly loads can make reasonably accurate forecasts of the demand for some years in advance.

\section{The Rubber Research Institute of Malaya.}

IHE first issue of the Quarterly Journal of the Rubber Research Institute of Malaya, Kuala Lumpur, January 1929, bear's witness to the very active steps that have been taken to put the new Research Institute into working order. The director, Dr. G. Bryce, arrived in Malaya to take up his duties in September 1926. Some local appointments were made during the autumn of that year, and the other officers of the station were gradually brought in during 1927 and 1928, the seventeenth appointment being made in November 1928. By June 1927 the heads of the chemical, pathological, botanical, and soils divisions of the Institute were appointed, and engaged in visiting the neighbouring rubber research stations in Sumatra and Java. Temporary laboratory accommodation was provided by adapting a bungalow, and four months after the arrival of the heads of divisions in Malaya they had presented programmes of work for their respective divisions for the consideration of the Board of Control.

In this first issue of the Quarterly Journal, brief summaries of the work of the different divisions are given, for the period up to Sept. 30, 1928. These show that the officers appointed have lost no time in grappling with the many-sided problems presented by the commercial cultivation of the rubber plant, and the preparation of the latex for market.
The bulk of the journal consists of articles by various officers of the Institute upon many of the interesting problems that arise in connexion with research upon the growing and preparation of rubber. Besides being of interest to the rubber planters, many of these articles have special interest to botanists, colloid chemists, and other investigators of agricultural and industrial problems, who are not directly concerned with the rubber industry. Occasionally, however, a certain obscurity of expression makes some of these articles difficult to follow, and particularly if the Research Institute wishes to carry interested growers with it in its investigations through the medium of its journal, it would seem worth while to expend more time and trouble upon the form in which these in vestigations, often themselves of great intrinsic interest, are described in print.

Dr. Haines discusses a topic of very general interest in countries with a tropical rainfall when he reviews the pros and cons of methods of silt pitting as a means of defence against excessive soil erosion. Experience which this investigator obtained in the classic experimental fields of Rothamsted is here utilised to visualise a soil problem specially characteristic of tropical and sub-tropical conditions. The botanical division reports much active work upon vegetative propagation. Mr. Mann, fresh from his contact with methods of

No. 3096, VoL. 123] 
fruit culture at the Experimental Station at Long Ashton, near Bristol, discusses the conditions governing successful bud unions in Malaya, where vigorous growth of shoot and scion at the time of union, together with fair humidity in the weeks following the budding operation, seem the most essential conditions for success.

Messrs. A. R. Sanderson and H. Sutcliffe give an account of some very valuable selection work on rubber they have had in progress before the formation of the Institute. These experiments confirm the general impression that the selection of high yielding stock on any other basis than the yield of dry rubber over a long period of tapping, can, as yet, only be made with considerable uncertainty.

The creation and propagation of high yielding strains - which Dr. Weir, the head of the pathological division, reminds the reader may be at any time required endowed with resistance to some newly introduced pathoger, such as the South American leaf blight, which Dr. Weir has studied in its native habitat-can obviously not be neglected by the Rubber Research Institute. Mr. Morris states that during a season's observations no pollen-carrying insect has been seen to visit the female flowers of Hevea, which, it must be remembered, is not of Malayan origin, but an introduced plant isolated from its normal insect visitors. Artificial pollination is successful between various selected clones, and a few seedlings have thus been obtained for further trial, but self-pollination within the clone is usually negative in result. The further analysis of the conditions, both internal and external, that contribute to successful pollination and fertilisation, is a promising field of investigation.

Many other points of detail as to the chemical properties of the rubber, its preparation and various commercial defects, diseases of cover crops, of young, budded plants, etc., are dealt with in this first number of the new journal. There is no doubt that if this standard is maintained, the Quarterly Journal of the new Rubber Research Institute will be a publication of permanent scientific value.

\section{Association of Technical Institutions.}

r [HE annual general meeting of the Association of 'Technical Institutions was held in the Grocers' Hall, London, on Feb. 22 and 23. As is customary, the installation of the president took place at the opening session, and, distinguished as have been the occupiers of the presidential chair in the past, the new president, Sir J. E. Kynaston Studd, is one of whom the Association may be justly proud. By a happy chance, the year of his presidency coincides with his year of office as Lord Mayor of London. But it is not only the civic honours that are his which distinguish him in and qualify him for his new office. For some years now his activities in connexion with the Regent Street Polytechnic, of which he is president, have been well known.

Since he was therefore in a position to speak to the Association as an expert, Sir Kynaston Studd's presidential address was expected to be one of unusual authority. Nor was his audience disappointed. His review of the work of such recent committees as the Balfour Committee on Trade, the Malcolm Committee on Education and Industry, and the Emmott inquiry into technical education and industry, was broad and illuminating. The conclusion he drew from the reports of these committees may be summarised by saying that, although the Board of Education is now in a position as a result of the work done to do much to help technical education to attain the greater place it merits in our system, a great deal of the task of getting industry to come more and more to the technical college for informert help must be borne by such associations as the A.T.I. In connexion with all this, he did not attempt to minimise the work done by the Atholl Committee on Examinations, but it was clear that he was closely in touch with the views of the majority of those engaged in technical education when he suggested that examinations are the least important part of the work of technical education. We were glad, too, to note that he pressed home a vital point to which attention has already been directed in these columns (see Nature, Nov. 12, 1927, p. 681 ; and July 28, 1928, p. 121) - the status of the craftsman must be equal to that of any other worker; an end which will be difficult to attain unless industry is prepared to guarantee the same conditions of permanency to craftsmen as it does to clerks and others of the administrative staffs.

Papers read and discussed during the meetings included "Broadcasting and its Relation to Further" Education," by Mr. C. A. Siepmann, of the B.B.C.; "Industrial Safety," by Sir Gerald Bellhouse, H.M. Chief Inspector of Factories ; and "Technical Training for Women," by Miss E. E. Cox, of the L.C.C. Barrett Street Trade School.

In connexion with the paper on industrial safety, a visit was arranged to the Home Office Industrial Museum, where safety devices are set out in admirable fashion. Few people, as Sir Gerald Bellhouse pointed out in his paper, realise how big a toll accidents make upon industry. Yet the most recent figures show that 156,974 accidents (of which 973 were fatal) were reported during 1927 to the Factory Department. Out of these cases, those which come within the Factory and Workshop Acts mean that each year about $£ 2,500,000$ is paid in compensation : additional administrative, legal and medical costs must bring the figure to not less than $£ 5,000,000$ per annum. Statistics such as these should in themselves be sufficient to make employers, employees, staffs, and students of engineering schools in universities and technical colleges desire to visit the Home Office Industrial Museum, where may be seen all the best methods of preventing danger to life and limb which have become incidental to industrial processes.

\section{University and Educational Intelligence.}

CAMBridge.-Mr. E. N. Willmer has been appointed University lecturer in physiology.

The following grants have been made from the Balfour Fund : $£ 100$ to Dr. C. M. Yonge, for researches at Honolulu and elsewhere in reference to his experiments on the Great Barrier Reef; $£ 50$ to $\mathrm{Mr}$. F. S. Russell, for researches on the plankton of the Great Barrier Reef region.

Birbai Sahni, Emmanuel College, has been approved for the degree of doctor of science.

LeEds.-Mr. F. J. Dent has been appointed gas research chemist in the Department of Coal Gas and Fuel Industries in succession to Dr. A. Parker, who has resigned in order to take up a responsible post with the Water Pollution Section of the Department of Scientific and Industrial Research. Mr. Dent has been working in the Department under Prof. J.W. Cobb for the past two years upon the gasification of special cokes in oxygen, and upon heat treatment in hydrocarbon and other gases as a factor influencing the reactivity of coke.

$$
\text { No. 3096, VoL. 123] }
$$

